\title{
Ranking Dairy Sires Using Genetic Selection Indices Based on Financial Investment Methods versus Lifetime Net Merit: Description and Spreadsheet ${ }^{1}$
}

\author{
Michael Schmitt and Albert De Vries ${ }^{2}$
}

\section{Introduction}

The purpose of this factsheet is to describe ways to rank dairy sires using genetic selection indices based on financial investment methods versus Lifetime Net Merit. The factsheet also discusses a spreadsheet that contains the calculations. This publication is designed for dairy farmers and their advisors.

\section{Description}

Ranking dairy bulls to make a sire selection decision is most easily done based on a single value from a selection index. For dairy farmers with a profit-driven focus, the best selection index is a representation of the money that could be made from the genetics supplied by the bull. Converting the predicted transmitting abilities (PTA) of genetic traits into one PTA for predicted profitability is at the heart of an economic genetic selection index, such as the Lifetime Net Merit (LNM\$) developed by the USDA. The LNM\$ is one of the most popular selection indices in the United States and is also widely used around the world.

The LNM\$ gives every animal credit for production during 2.78 lactations, which is the average number of lactations for Holsteins in the United States. In reality, the length of the expected lifetime is not the same for all animals and depends on the PTA of the trait of Productive Life (PL), which can be used to help predict the individual lifetime of the animal. The PTA for PL is used in the LNM\$ formula as an adjustment for replacement costs. If the PTA for PL is high, we expect the animal to stay longer in the herd, and the replacement cost per unit of time (2.78 lactations in this case) to be lower. If all other traits remain the same, the animal with a higher PTA for PL is more profitable. This means that a higher PTA for PL results in a higher LNM\$.

Digging deeper in the LNM\$ formula, there are traits that are expressed every lactation, and other traits that are expressed only once in an animal's lifetime. For example, a genetic trait such as pounds of milk fat generates net revenues in each lactation, and the total value of fat pounds in the animal's lifetime clearly depends on the number of lactations. However, this does not apply to all genetic traits because a trait like livability, which estimates the change in the percentage of animals that leave the herd alive, generates net revenue only when the animal leaves the herd. The value of a trait like livability is not dependent on the number of lactations the animal stayed in the herd.

In the LNM\$ formula, every animal gets credit for 2.78 lactations for traits that generate net revenue in every lactation, such as fat pounds and daughter pregnancy rate, independently of how long we expect the animal to actually stay in the herd. We challenged this assumption. Say an

1. This document is AN364, one of a series of the Department of Animal Sciences, UF/IFAS Extension. Original publication date May 2021. Visit the EDIS website at https://edis.ifas.ufl.edu for the currently supported version of this publication.

2. Michael Schmitt, PEAK program analyst, URUS Group, and former graduate student, Department of Animal Sciences; and Albert De Vries, professor, dairy management and economics, Department of Animal Sciences; UF/IFAS Extension, Gainesville, FL 32611.

The Institute of Food and Agricultural Sciences (IFAS) is an Equal Opportunity Institution authorized to provide research, educational information and other services

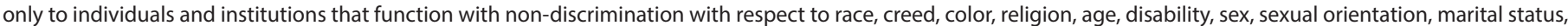

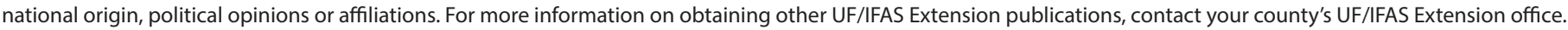
U.S. Department of Agriculture, UF/IFAS Extension Service, University of Florida, IFAS, Florida A \& M University Cooperative Extension Program, and Boards of County Commissioners Cooperating. Nick T. Place, dean for UF/IFAS Extension. 
animal with a high PTA for fat pounds is expected to have a productive lifetime shorter than 2.78 lactations. The animal should not get credit for 2.78 lactations of high fat, but fewer. A selection index that addresses this problem would more appropriately estimate the lifetime profitability of a bull's genetics.

Comparison of animals with different PTA for PL is an example of a classical investment analysis for investments with unequal lifetimes. In this analysis, every animal gets credit for the expected number of lactations for traits that generate net revenue in every lactation.

We created a new economic genetic selection index called the Annualized Net Present Value (ANPV) to address this issue by framing the total genetic value of an animal as a financial investment. Because PTAs are converted into expected net revenues and the expected length of the animal's lifetime can be predicted, each animal's genetics can be viewed as a financial investment with expected net revenues depending on the lengths of the investment. Because the length of expected lifetime varies between animals, the expected cash flows were standardized to an annual basis. A higher profit per unit of time (e.g., a year) is often the goal, not simply higher profit in a lifetime. When we constructed our new selection index, we used the same economic values for traits as used in the 2017 LNM\$ formula. In our study, we also calculated the ANPV index for 1,500 marketed Holstein sires from the December 2017 genetic evaluation. It turned out that the ranking of bulls based on the ANVP index was similar, but not the same as the ranking based on LNM\$. Some high-ranking bulls dropped or increased dozens of places in the rankings.

For example, Bull A has a PL of +11.5 months, only +19 fat pounds, and $+717 \mathrm{LNM} \$$. For easy comparison on an annual basis, we divided the LNM $\$$ by the assumed length of lifetime (2.78 lactations, assuming each lactation was one year) to equal $\$ 258$ per year. The bull's PL indicates that his daughters will remain in the herd for a long time, but they will generate low net revenues from traits that are expressed each lactation. In contrast, Bull B has a similar annualized $\mathrm{NM} \$$ of $\$ 262$, but a PL of +2.7 months and +112 fat pounds set his daughters up to be high-fat producers with shorter lives. When the net revenue from genetic traits is standardized with the ANPV approach, Bull A is rewarded for more net revenue from lactation traits beyond the standard lifetime length of 2.78 lactations. Bull B is penalized for a shorter lifetime. The $\$ 4 /$ year genetic advantage for Bull A in the annual NM\$ has now changed to a $\$ 7 /$ year genetic advantage for Bull B when considering these differences in animal lifetimes with this new index.

\begin{tabular}{|l|c|c|}
\hline & Bull A & Bull B \\
\hline Productive Life PTA & 11.5 & 2.7 \\
\hline Fat PTA & 19 & 112 \\
\hline NM PTA & 729 & 717 \\
\hline Annualized NM\$ & 262 & 258 \\
\hline ANPV & 277 & 284 \\
\hline AVOC & 255 & 293 \\
\hline
\end{tabular}

However, the financial impact of the selection decision goes beyond the lifetime of the animal. The length of the lifetime determines the genetic value of the animal that replaces the original animal. The replacement of the daughter of Bull A is genetically superior to the replacement of the daughter for Bull B because more time has passed, and the average genetic value increases with genetic progress in the breed. Unfortunately, ANPV does not account for this problem because it assumes the replacement animal is identical to the original animal.

To tackle this problem, a second economic genetic selection index was created to account for the opportunity cost of delaying the replacement animal from entering the herd. We called this index the Annualized Value with Opportunity Cost (AVOC). A distant time in the future was selected to anticipate the differences of genetic value of future animals from the trend of genetic progress based on the length of lifetime of the original animal. Animals with extended lifetimes from PL and low net revenue should be penalized for taking up space which could be filled by a more productive and profitable cow.

If we continue from our previous example, Bull $\mathrm{A}$ is now penalized for the delay in the replacement animal entering the herd and thus incurs an opportunity cost. The previous \$4/year advantage for Bull A in annual NM\$ has changed to a \$38/year advantage for Bull B using AVOC. What seemed to be similar genetic values and a simple choice of the best bull with LNM\$ change when the faults in LNM\$ are corrected with this new approach.

On an industry level, LNM\$, ANPV, and AVOC rank animals similarly but not the same. Despite the high correlations, considering the genetic value for animals as a financial investment with varying lengths and opportunity cost for delayed replacement is a new approach for a genetic selection index. This approach more accurately captures the net revenue generated from genetics and more correctly ranks bulls as investment opportunities. Profit-focused farmers consistently improving their replacement genetics should consider use of these new indices. However, the new indices are not publicly available. The new indices are 
available for publicly marked Holstein sires upon request from the authors. The development of the new indices was published in the September 2019 issue of the Journal of Dairy Science.

\section{Spreadsheet}

We developed a spreadsheet with the ANPV and AVOC calculations, which is available for download here. The spreadsheet is updated with the 2018 LNM\$ economics weights and traits and loaded with bulls from the December 2019 genetic evaluation. Users may edit the spreadsheet as they see fit but need to refer to this EDIS publication for distribution or publication of its results.

\section{Reference}

Schmitt, M. R., P. M. VanRaden, and A. De Vries. 2019.

"Ranking Sires Using Genetic Selection Indices Based on

Financial Investment Methods versus Lifetime Net Merit." J.

Dairy Sci. 102 (10): 9060-9075. doi: 10.3168/jds.2018-16081 